during pregnancy, and histological changes in the decidua and fetal organs resemble those present after naturally acquired maternal disease. $^{3}$ Until more information has been collected, pregnancy must remain a contraindication to rubella vaccination. Nevertheless, inadvertent vaccination during pregnancy will undoubtedly still occur, and unfortunately many who have not been screened for rubella antibodies will be advised to have their pregnancies terminated. We think that this fetal wastage could be considerably reduced, since our results show that if patients not screened for rubella antibodies before vaccination have virological assessment within eight weeks of receiving RA $27 / 3$ vaccine, it is possible to determine whether their antibody results from recent vaccination or from past infection. Results after vaccination with Cendehill vaccine are somewhat less reliable, however, unless the vaccine has induced a reasonably high $\mathrm{HAI}$ antibody response (for example, $\geqslant 1 / 32$ in our study).

This investigation was supported by funds from the National Fund for Research into Crippling Diseases.

1 Department of Health and Social Security, Rubella Prophylaxis, Circular 9/70. London, DHSS, 1970.

${ }^{2}$ Office of Population Census and Surveys. Monitor Series, AB 77/0. London, HMSO, 1977.

${ }^{3}$ Modlin, J F, et al, New England fournal of Medicine, 1976, 294, 972.

4 Al-Nakib, W, Best, J M, and Banatvala, J E, Lancet, 1975, 1, 182.

5 Quirin, E P, Nelson, D B, and Inhorn, S L, Applied Microbiology, 1972, 24, 353.

(Accepted 21 September 1977)

Department of Virology, St Thomas's Hospital and Medical School, London SE1 7EH

J E BANATVALA, MD, FRCPATH, professor of clinical virology

A DRUCE, FIMLs, chief technician

JENNIFER M BEST, BSC, PHD, senior lecturer

W AL-NAKIB, MA, PHD, research associate (now assistant professor of microbiology, University of Kuwait)

\section{Sulphasalazine rectal enemas : topical method of inducing remission of active ulcerative colitis affecting rectum and descending colon}

The Truelove regimen, which includes prednisolone and sulphasalazine by mouth, is an effective treatment for acute active ulcerative colitis with total colonic involvement, ${ }^{1-3}$ though relapse may occur and the steroid component may aggravate underlying disorders such as diabetes mellitus. Intolerance to sulphasalazine by mouth is common, with rash, haemolytic anaemia, nausea, and vomiting. ${ }^{4}$ Suppositories of sulphasalazine have been used in ulcerative colitis, ${ }^{5}$ but we report for the first time the use of sulphasalazine enemas.

\section{Patients, methods, and results}

We selected 10 patients with acute ulcerative colitis (five male, and five female) of whom five were in relapse and five had not previously been treated. All had severe clinical disease with loss of the normal mucosal vascular pattern and friability of the mucosa on light swabbing. Sigmoidoscopy and rectal biopsy were performed in all cases before and after introduction of the enemas. Multiple rectal biopsy specimens were taken to obviate sampling errors. All pretreatment specimens showed acute active ulcerative colitis. Multiple post-treatment biopsies were performed on days 8-213. Enemas were prepared by dissolving two sulphasalazine tablets ( $1 \mathrm{~g}$ sulphasalazine) in a glass of water and administered twice daily with a bulb enema syringe. All patients found the treatment acceptable.

Five patients in relapse after treatment with the Truelove regimen or maintenance doses of sulphasalazine by mouth or both entered a period of maintained clinical remission of 11 months with sulphasalazine enemas. In one of these patients steroids had greatly aggravated an underlying diabetes mellitus, necessitating insulin treatment. Of the patients who had not been treated previously, four became asymptomatic after receiving sulphasalazine enemas as the initial treatment. The remaining patient was severely ill on admission and was started on the Truelove regimen together with sulphasala-

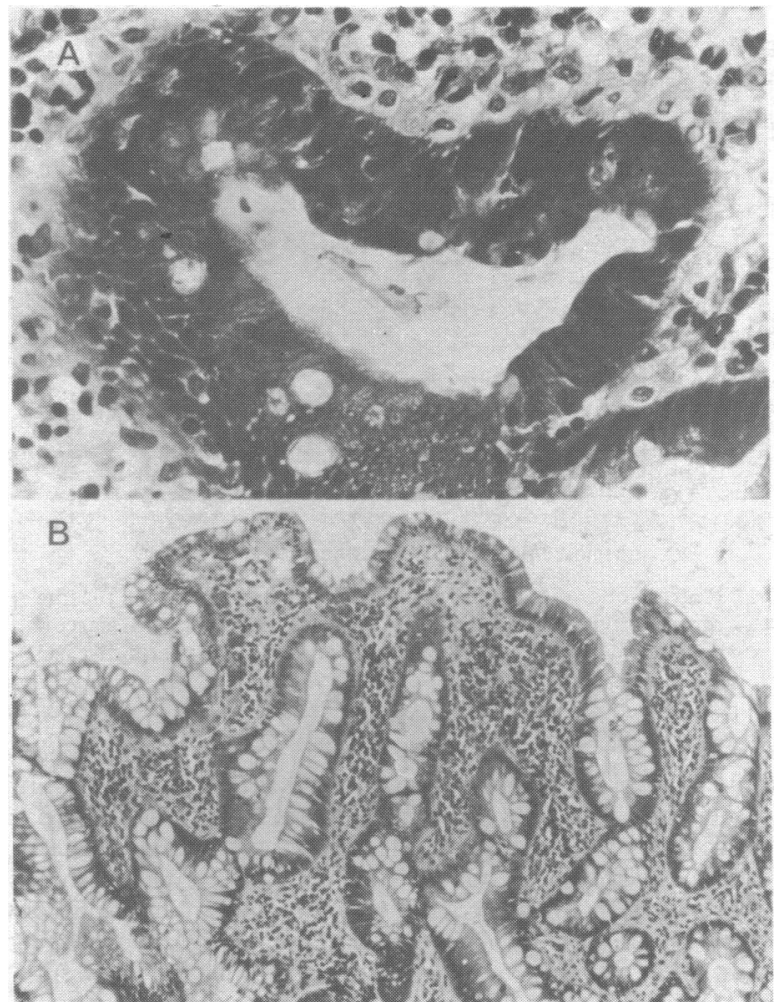

Rectal biopsy appearances before and after treatment with Truelove regimen and sulphasalazine enemas. Top: Before treatment. Gland showing severe borderline dysplasia. (Haematoxylin and eosin. $\times 233$.) Bottom: Fifteen days after treatment. Return of normal pattern with no dysplasia ( $\mathrm{H}$ and $\mathrm{E}$. $\times 60$.)

zine enemas. There was a remarkable clinical and sigmoidoscopic improvement, and after 10 days he was discharged on maintenance treatment with sulphasalazine enemas and sulphasalazine and steroids by mouth. $\mathrm{He}$ relapsed after four months but again responded rapidly to the Truelove regimen and sulphasalazine enemas. He continued in remission for three months and gained $13.6 \mathrm{~kg}$.

Only one patient, in whom biopsy was carried out nine days after treatment, showed no histological evidence of improvement. The other nine patients showed remarkable improvement, which began as early as eight days after treatment and was maintained for up to 11 months (see figure).

\section{Comment}

The mechanism by which sulphasalazine enemas exert an effect extending back to the splenic flexure is not understood, though in patients with generalised ulcerative colitis steroid enemas mixed with contrast material have been shown to reach the hepatic flexure. Our results suggest that the topical application of sulphasalazine to rectal and colonic mucosa in acute ulcerative colitis is highly effective, and thus sulphasalazine enemas are a useful adjunct to the Truelove regimen. The method is cheap and well tolerated.

Requests for reprints should be addressed to: Dr Cyril Abrahams, 1609 Lister Buildings, Jeppe Street, Johannesburg, South Africa.

1 Truelove, S C, and Jewell, D P, Lancet, 1974, 1, 1067.

2 Truelove, S C, British fournal of Clinical Practice, 1974, 28, 5.

3 Lennard-Jones, J E, Canadian fournal of Surgery, 1974, 17, 422.

4 Das, K M, et al, New England fournal of Medicine, 1973, 289, 491.

5 Schulz, U, et al, Wiener Zeitschrift für innere Medizin und ihre Grenzgebiete, $1973,54,185$.

(Accepted 29 fune 1977)

Brenthurst Clinic, Parktown, Johannesburg

HAROLD SEREBRO, FRCP, consultant physician

SHOLEM KAY, DIPSURG(RAND), consultant surgeon

STANLEY JAVETT, FRCS, consultant surgeon

Lister Buildings, Johannesburg

CYRIL ABRAHAMS, FRCPATH, consultant pathologist 